\title{
Práticas interdisciplinares em educação ambiental na educação básica: o que indicam as pesquisas acadêmicas brasileiras de 1981 à 2012
}

Marilac Luzia de Souza Leite Sousa Nogueira marilac nog@hotmail.com https://orcid.org/0000-0003-3641-2165 Secretaria Municipal da Educação de Campinas; Universidade Estadual de Campinas (Unicamp), Campinas, SP, Brasil

Jorge Megid Neto megid@unicamp.br https://orcid.org/0000-0003-0829-9548 Universidade Estadual de Campinas (Unicamp), Campinas, SP, Brasil

\section{RESUMO}

A pesquisa teve por objetivo analisar as práticas interdisciplinares em Educação Ambiental (EA) propostas ou implementadas na educação básica, descritas em teses e dissertações brasileiras. A multidimensionalidade presente nas questões ambientais e a importância da abordagem da EA, em todos os níveis escolares, numa perspectiva interdisciplinar, motivou a escolha do tema deste estudo. Buscou-se investigar a seguinte questão central: que concepções de Interdisciplinaridade, Ambiente e EA podem ser depreendidas da análise das pesquisas acadêmicas sobre práticas interdisciplinares em Educação Ambiental na educação básica? De um universo de 2.763 trabalhos, defendidos entre 1981 e 2012 e constantes do Banco de Teses do Projeto EArte, foram localizadas apenas 21 pesquisas relativas a esse objeto de estudo. Os documentos foram lidos, descritos e classificados quanto aos dados institucionais (autor, orientador, ano de defesa, instituição de ensino superior, programa de pós-graduação, unidade federativa, dependência administrativa, grau de titulação acadêmica) e quanto à prática interdisciplinar em Educação Ambiental, conforme os descritores: ano ou série escolar, tipo de escola, disciplinas abrangidas nas práticas, métodos e estratégias de ensino, recursos e materiais didáticos, tipo de integração curricular, referencial teórico-pedagógico, público envolvido e a interação entre ele, nível de integração disciplinar, concepção de ambiente, concepção de EA e sua manifestação curricular. As pesquisas concentraram-se, fortemente, na década de 2000, com dezoito trabalhos. As práticas analisadas, em sua maioria, centraram suas ações nos anos iniciais do ensino fundamental, desenvolvidas a partir de temas geradores ou projetos de ensino. Os materiais didáticos utilizados foram os comumente encontrados nas escolas, de baixo custo, além de atividades externas. As ações pedagógicas vincularam-se às propostas curriculares das escolas e as disciplinas mais envolvidas (sempre em conjunto com outras) foram Geografia e Língua Portuguesa, seguidas de Matemática, Ciências, História e Artes. Os pais e a comunidade assumiram papel cooperativo nas práticas e notou-se uma relação hierárquica quanto à decisão da proposta de trabalho por parte dos professores e pesquisadores para com os alunos; contudo, tanto no aceite da proposta, quanto no desenvolvimento das atividades pedagógicas, observou-se intensa participação dos estudantes. Dezoito práticas foram consideradas como interdisciplinares e três pluridisciplinares. Nas práticas analisadas predominou a concepção de ambiente integrado e de Educação Ambiental numa perspectiva crítica, manifestada como elemento essencial e integrado ao currículo escolar. Conforme a análise das pesquisas revelou, muito embora os professores demonstrassem interesse pela EA e pela prática interdisciplinar, não se encontravam preparados para esse tipo de trabalho, ao que se sugere investimento na formação continuada e revisitação nos cursos de formação inicial de professores.

PALAVRAS-CHAVE: Educação Ambiental. Interdisciplinaridade. Prática Pedagógica. Educação Básica. Estado da Arte. 


\section{INTRODUÇÃO}

Esta investigação teve por objetivo analisar as práticas interdisciplinares em Educação Ambiental realizadas na Educação Básica e tratadas em teses e dissertações brasileiras. Configura-se em um estudo do tipo estado da arte sobre a produção acadêmica brasileira no campo da Educação Ambiental (EA). O trabalho esteve inserido no conjunto de ações do projeto interinstitucional denominado Estado da Arte da Pesquisa em Educação Ambiental no Brasil (Projeto EArte), desenvolvido desde 2008 (ver www.earte.net).

Tanto a Educação Ambiental quanto a Interdisciplinaridade são temas que ganharam impulso no Brasil a partir da década de 1970, constituindo-se em campos temáticos e de pesquisa relativamente novos, sobretudo no que diz respeito à integração desses campos.

A interdisciplinaridade toma corpo como uma nova forma de conceber o conhecimento disciplinar, que se desenvolveu em uma especialização crescente, especificando, cada vez mais, seu objeto de estudo, o que muito tem contribuído para o avanço dos conhecimentos da humanidade. Todavia, convivemos com problemas contemporâneos que se apresentam complexos e interligados, que solicitam a confluência das colaborações disciplinares, impulsionando a contribuição interdisciplinar na atualidade, o que pode ser constatado nas colaborações disciplinares que envolvem a bioquímica, a neurociência, a engenharia genética entre outras.

Segundo Jantsch (1973), Piaget (1973), Japiassu (1976) e Fazenda (1995) entre outros, a escola de educação básica ou de educação superior é convocada a contribuir na formação de sujeitos que compreendam não somente a importância do avanço disciplinar, mas, também, a necessidade do foco interdisciplinar para a busca da compreensão de determinados objetos de estudo, de modo a formar interações que, certamente, contribuirão para um significativo avanço no campo das ciências e da sociedade.

Essa (inter)ação se manifesta de modo a favorecer um melhor trânsito entre as várias disciplinas ou conteúdos curriculares, com vistas a possibilitar ao estudante a construção do conhecimento pautado na complexidade em que se apresentam determinados temas de estudo, alinhavados com a dinamicidade da vida e com as experiências cotidianas do aluno.

No presente estudo, foram analisadas as práticas interdisciplinares descritas/propostas/implementadas nas teses e dissertações em Educação Ambiental, identificando suas principais características quanto a relações entre professores e estudantes, integração entre as disciplinas curriculares envolvidas, as concepções de Ambiente e Educação Ambiental subjacentes às práticas investigadas entre outros aspectos.

\section{EDUCAÇÃO AMBIENTAL E INTERDISCIPLINARIDADE: APORTES TEÓRICOS}

As questões de complexidade que constituem o ambiente natural/social são análogas às que justificam a necessidade da interdisciplinaridade na ciência e na educação. Observamos o destaque dessa ocorrência desde a segunda metade do século $\mathrm{XX}$, momento em que emerge um novo contorno de ciência e de 
conhecimento e compreensão de ambiente, que evidencia a interdependência entre os diversos fatores implicados nos mais diferentes objetos de estudo, sejam eles considerados de ordem prática ou epistemológica.

Vários documentos, frutos de Tratados e Conferências mundiais no campo da EA, apontam a interdisciplinaridade como referência em processos educativos no tratamento que deve ser dispensado à EA. Desse modo, a implementação de programas que atendam a essas exigências foi impulsionada, sobretudo a partir de 1972, pela Conferência da Organização das Nações Unidas (ONU), em Estocolmo, que marcou os debates em torno da questão ambiental, resultando no conhecimento da EA como elemento crítico para a crise ambiental vivida, conforme podemos observar em algumas das recomendações decorrentes dessa Conferência: "A Educação Ambiental é o resultado de uma reorientação e articulação de diversas disciplinas e experiências educativas que facilitam a percepção integrada do meio ambiente, tornando possível uma ação mais racional e capaz de responder às necessidades sociais" (BRASIL, 2020, p. 1).

Tendo como um de seus princípios básicos o enfoque interdisciplinar em uma abordagem global das questões ambientais, o documento se refere à escola como um espaço determinante para que essas ações sejam implementadas de modo sistemático.

À época, em decorrência dos compromissos assumidos pelo governo brasileiro diante da crise ambiental declarada, foram implementadas políticas públicas nessa direção. Desde então, houve a criação de grupos de estudo, programas, secretarias de meio ambiente, legislações específicas e toda uma gama de ações de ordem pública. No que concerne ao campo educacional brasileiro, tivemos a incorporação das questões da EA em vários currículos municipais e estaduais da educação básica, culminando com a inserção da temática ambiental em âmbito educacional nacional, como tema transversal dos Parâmetros Curriculares Nacionais (PCN), implantados a partir de 1996, transversalidade, esta, que teve como subjacência a interdisciplinaridade (BRASIL, 1996).

Entendemos que a transversalidade e a interdisciplinaridade indicadas pelos PCN são alternativas para um trabalho pedagógico disposto a realizar uma abordagem transversal que busca inter-relacionar as disciplinas curriculares. $\mathrm{Na}$ educação, a proposta da transversalidade oferece rica possibilidade de tratar as questões ambientais de modo que transversem as disciplinas curriculares, na tentativa de oferecer ao aluno a compreensão da complexidade e da inter-relação dos diversos conteúdos curriculares.

Como elementos subjacentes às nossas análises, estabelecemos a compreensão das concepções de Ambiente, Educação Ambiental e Interdisciplinaridade.

Para a concepção de Ambiente, adotamos o trabalho de Rink (2014), que, baseada em variados autores do campo da EA, sistematiza quatro concepções: a) Ambiente Abiótico: quando se consideram apenas os fatores físicos, químicos e geológicos do ambiente, no qual o seres vivos (e o ser humano) estabelecem uma relação de exterioridade; b) Ambiente Abiótico + Biótico Sem a Presença Humana: definida pela inclusão dos seres vivos não humanos e não vivos como parte do ambiente e, do mesmo modo que na visão anterior, o homem é excluído dessa esfera conceptiva; c) Ambiente Integrado com Perspectiva Utilitária: em que se 
consideram os elementos bióticos e abióticos e sua inter-relação e interdependência, incluindo o homem. $O$ ambiente, nesse caso, é concebido como fonte de recursos (bióticos e abióticos) necessários à sobrevivência humana e expressa uma visão pragmática e utilitarista; d) "Ambiente Integrado": em que se consideram todos os fatores bióticos, abióticos e político-sociais na composição do ambiente em completa inter-relação e interdependência. O ambiente é concebido pela composição de elementos bióticos (incluindo o ser humano), abióticos e das relações sociais nele presentes, de ordem histórica, política, econômica, social, cultural entre outras, o que remete à consideração da multidimensionalidade e complexidade ambiental.

As concepções de Ambiente e de Educação Ambiental estão estreitamente ligadas e vários autores dedicaram seus estudos a essa inerente relação, como Lima (1999), Amaral (2004), Brügger (2004), Layrargues (2009) entre outros. Optamos por assumir o trabalho de Layrargues e Lima (2014) como referencial analítico das práticas interdisciplinares descritas e investigadas em nosso corpus documental.

Layrargues e Lima (2014, p. 7) mapearam as macrotendências pedagógicas da EA no Brasil e as definiram em três vertentes: "Conservacionista", "Pragmática" e "Crítica". A macrotendência "conservacionista", segundo os autores, abrange correntes educacionais comportamentalistas, de alfabetização ecológica e de autoconhecimento, atributos que segregam a possibilidade de uma EA voltada para as transformações sociais, muito embora nela sejam encontrados aspectos de interdependência, parceria, diversidade, flexibilidade. São identificados princípios ecológicos básicos, limitantes de uma abrangência participativa cidadã nas questões ambientais presentes na atualidade.

A macrotendência "pragmática" é caracterizada, por Layrargues e Lima (2014, p.7), por ações de ordem do desenvolvimento sustentável, nas quais há, por exemplo, preocupação com os resíduos produzidos pelo consumo humano sem ultrapassar, contudo, a discussão do reaproveitamento desses resíduos, o que mantém díspares as relações na sociedade. Essa macrotendência adequa-se à sociedade neoliberal, não questiona as relações de produção nem as de poder, também faz persistir a crença na neutralidade da ciência e seu poder de resolução dos problemas ambientais. Os apelos de reação aos problemas ambientais vividos na contemporaneidade giram em torno do protagonismo individual das pessoas e das empresas, provocando um estado de esvaziamento das verdadeiras causas.

A macrotendência "crítica" (LAYRARGUES; LIMA, 2014, p.7) nasce da adoção de pertença de uma EA que considera a complexidade na análise das causas ambientais. Suas derivações são compreendidas em um universo que reconhece tanto o ponto de vista individual, quanto o coletivo, o social, o científico, o político, o econômico entre outros. A Educação Ambiental, assim concebida, torna-se lócus de reflexão a respeito da situação ambiental vivida. Lócus no qual, inegavelmente, se consideram todos os aspectos socioculturais implicados, bem como as relações históricas de poder nela manifestas. Esses fatores sócio históricos são recursos que contribuem para uma análise crítica que ofereça condições mais simétricas de participação da sociedade nos encaminhamentos que envolvem as questões ambientais e os rumos a serem decididos, de forma a engajar uma democrática e efetiva participação cidadã. 
Para fundamentar as relações da EA com as práticas escolares ou, de maneira mais global, com o currículo escolar, tomamos por referência Amaral (2005). O autor considera sete diferentes modos/concepções de manifestação da EA no currículo escolar que se manifestam como elemento: Implícito/Oculto; Complementar; Suplementar; Gerador; Unidade Programática; Transversal; Essencial.

A EA como elemento implícito/oculto no currículo escolar, conforme Amaral (2005), caracteriza-se pela preocupação exclusiva em apresentar aos estudantes os conhecimentos científicos e suas derivações tecnológicas, tratando-os de um modo extensivamente conteudista, que sustenta um discurso limitante no que diz respeito ao avanço em discussões sobre a aplicabilidade do conhecimento científico e sobre seus impactos socioambientais. Nesse contexto curricular, o ambiente se apresenta de modo implícito e oculto, transmitindo uma visão muito bem definida sobre concepção de ambiente e EA, notadamente atrelada aos aspectos ideológicos que enaltecem a manutenção do poder e a não participação coletiva nas decisões que implicam nos reflexos socioambientais delas decorrentes.

A manifestação da EA como elemento curricular complementar se dá quando ela é apresentada de modo ilustrativo, a partir de um determinado conteúdo, sendo utilizada como ponto de chegada com fim em si mesmo, podendo se configurar, até mesmo, como um apêndice do processo educativo, um complemento, um adicional ilusório ou meramente ilustrativo que se agrega ao conteúdo curricular trabalhado.

O enfoque da EA enquanto elemento suplementar se configura pela utilização reducionista da metodologia de projetos para tratar de temas nem sempre pertencentes ao conteúdo curricular, podendo-se estudar temas ligados aos fenômenos naturais e os impactos provocados no ambiente pelo ser humano (AMARAL, 2005). Geralmente, esse trabalho é concretizado sob a forma de pesquisa escolar feita pelos alunos, ou de estudos do meio, ambos tomados como ponto inicial ou final do conteúdo proposto. Em muitos casos, se configura como projetos envolvendo toda a comunidade escolar (alunos, professores, gestores, funcionários, familiares etc.), mas desconectados dos currículos desenvolvidos em cada disciplina. Ocorre, por exemplo, em atividades que vão acontecendo paralelamente às aulas regulares, ou mesmo quando se reserva um determinado período escolar para seu desenvolvimento, por exemplo projeto Água, projeto Lixo, projeto Reciclagem, projeto Biodiversidade entre outros. Claro que estudos e práticas escolares sobre tais temas ambientais também podem ocorrer sob perspectiva de outros elementos curriculares.

A EA como elemento gerador se manifesta por ações escolares pautadas em temas cotidianos de interesse do aluno, contudo os temas não ultrapassam o caráter figurativo-motivador-desencadeador dos conteúdos curriculares a ser cumpridos, configurando-se como um ponto de partida no qual reside a grande possibilidade de que os conhecimentos teóricos se esgotem, sem que sejam discutidos do ponto de vista dos conhecimentos científicos e tecnológicos. Correse o risco, de que venham a não ultrapassar os limites figurativos característicos dessa modalidade (AMARAL, 2005). 
A manifestação da EA como elemento de unidade programática se mostra em trabalhos escolares que propõem seu enfoque sob a forma de um tópico inserido em uma unidade do programa educacional, ou seja, temas ligados ao conteúdo trabalhado. Do ponto de vista metodológico, essas ações podem ser tradicionais ou inovadoras e os temas abordados podem servir como ponto de partida, de chegada, ou como fator intermediário no delineamento curricular e nas práticas escolares regulares e cotidianas.

A EA caracterizada como elemento transversal no currículo escolar considera temas que perpassam, longitudinalmente, várias ou todas as disciplinas curriculares, empreendendo um esforço coletivo dessas disciplinas e alcançando algum nível de interdisciplinaridade. Nessa modalidade existe a possibilidade de que as disciplinas se mantenham íntegras, mesclem-se ou, ainda, busquem ultrapassar suas fronteiras disciplinares.

$\mathrm{Na}$ modalidade de manifestação curricular da EA enquanto elemento essencial, seu tratamento se faz presente de forma intensa no desenvolvimento dos conteúdos curriculares, sob o enfoque de uma educação que privilegia o estudo que parte da realidade e do interesse dos alunos; o trabalho é intencional, vai além da simples promoção motivacional para a aprendizagem, os fenômenos estudados são intensamente explorados pelos alunos, sendo promovido o seu desenvolvimento conceitual e afetivo, considerados os limites de seu estágio psicológico e socioafetivo (AMARAL, 2005).

Adentrando, agora, nas noções sobre interdisciplinaridade e suas relações com a EA, devemos considerar que o estudo do ambiente remete a questões amplas e das mais diversas ordens ou dimensões (socio)ambientais. Assim, conceber a Educação Ambiental e a interdisciplinaridade tratadas na esfera educacional escolar, favorece o entendimento da complexidade do ambiente em suas mais diversas manifestações, o que motivou este estudo sobre as práticas interdisciplinares em Educação Ambiental descritas em teses e dissertações brasileiras.

Na educação, a proposta interdisciplinar oferece uma alternativa diferenciada para a abordagem disciplinar, como já dissemos, ao buscar estabelecer interconexões que permitam uma relação contextualizada e articulada entre os diversos conteúdos e disciplinas curriculares, os problemas reais e o contexto social vivido pelo estudante. Nesse sentido, a interdisciplinaridade traz consigo a concepção de um sujeito que se perceba interdisciplinar, que seja ativo na autoria de sua própria história de vida, na escola e no mundo, ultrapassando e ampliando uma compreensão apenas pluridimensional dos fenômenos estudados ou vividos (FAZENDA, 1995), de modo que o conhecimento seja dinamicamente interligado pelas diversas especialidades que o compõe, a se enriquecerem mutuamente.

Para Japiassu (1994), muito embora a interdisciplinaridade tenha se tornado um imperativo no final do século $X X$, passando a ser aceita e considerada no universo acadêmico, ela ainda não se efetivou de modo pleno, sobretudo no universo escolar. A esse fato, o autor atribui o estado em que se encontram os currículos escolares, ainda fortemente influenciados pela configuração do desenvolvimento científico moderno, onde os estudos são realizados nos contornos de cada especialidade. Sugere a necessidade de revisão dos currículos e da organização escolar para se alcançar uma perspectiva curricular interdisciplinar. 
Em trabalho anterior, e tomando por base o trabalho de Jantsch (1973), Japiassu (1976) propõe algumas gradações ascendentes das inter-relações disciplinares. Ele assume a seguinte terminologia: disciplinaridade, multidisciplinaridade, pluridisciplinaridade, interdisciplinaridade e transdisciplinaridade.

A disciplinaridade vem a ser a exploração científica especializada em certa área ou domínio homogêneo de estudo, ou seja, quando a disciplina é designada como uma ciência, como uma atividade de pesquisa, utilizada para significar o ensino de uma ciência enquanto disciplina curricular (JAPIASSU, 1976).

A multidisciplinaridade refere-se a um trabalho em que as disciplinas se apresentam de forma justaposta, sem necessariamente se envolver de modo coordenado em um trabalho de equipe entre as várias disciplinas. Essas se desenvolvem de maneira estanque, sem ultrapassar seus limites fronteiriços, não havendo intenção de estabelecer relações de uma disciplina com as demais.

A pluridisciplinaridade trata de um nível de pouca colaboração disciplinar. Ela se caracteriza pela justaposição de diversas disciplinas, havendo uma cooperação entre elas, mas com objetivos distintos e sem coordenação. Assemelham-se a esse tipo de ação trabalhos escolares desenvolvidos por professores de diferentes disciplinas, em que cada disciplina contribui com seu conhecimento para auxiliar no estudo e na compreensão de um determinado problema ou fenômeno, mas não ultrapassando o limite de uma simples colaboração.

A interdisciplinaridade é definida por Japiassu (1976, p.73) como "axiomática comum a um grupo de disciplinas conexas e definidas no nível hierárquico imediatamente superior, o que introduz a noção de finalidade", nesse caso ocorrendo inter-relação entre as disciplinas. Isso equivale, na escola, a uma ação docente e discente em que, diante de um determinado fenômeno a ser estudado, duas ou mais disciplinas colaboram entre si com um propósito único direcionado para um mesmo objetivo, transpondo seus limites de especialidade e sem que haja qualquer tipo de supremacia entre elas.

Por fim, a transdisciplinaridade é considerada pelo autor como o último grau das possíveis inter-relações disciplinares, sendo identificada pela "coordenação de todas as disciplinas e interdisciplinas de um sistema de ensino inovado, sobre a base de uma axiomática geral" (JAPIASSU, 1976, p.74). Nesse estágio, todas as disciplinas envolvidas estabelecem colaboração e cooperação mútuas, desaparecendo, inclusive, as fronteiras entre elas.

Com base nesses referenciais teóricos sobre concepção de ambiente e de Educação Ambiental, bem como das relações da EA com o currículo escolar e dos possíveis graus de inter-relação disciplinar, passamos a analisar as práticas pedagógicas escolares, na educação básica, retratadas em dissertações e teses no campo da Educação Ambiental.

\section{PROCEDIMENTOS METODOLÓGICOS DA INVESTIGAÇÃO}

Desenvolvemos uma pesquisa do tipo estado da arte, em que se busca inventariar, sistematizar, descrever, analisar e inferir características e tendências reveladas pelas produções acadêmicas (MEGID NETO, 2010), em nosso caso 
pesquisas sob a forma de dissertações e teses relacionadas a práticas interdisciplinares no campo da Educação Ambiental, implementadas ou propostas no contexto de um ou mais níveis escolares da educação básica. Procuramos responder à seguinte pergunta: que concepções de interdisciplinaridade, ambiente e Educação Ambiental podem ser depreendidas das descrições relatadas nas pesquisas acadêmicas sobre práticas interdisciplinares em Educação Ambiental na educação básica?

Para identificar e selecionar as dissertações e teses, o levantamento de dados foi realizado junto ao Banco de Teses e Dissertações em Educação Ambiental do Projeto EArte (disponível em www.earte.net). À época do levantamento, o Projeto EArte dispunha de informações abrangendo o período de 1981 a 2012.

Os documentos de interesse foram de início selecionados pelos termos disciplinar e integração. Com o primeiro termo, identificamos teses e dissertações que continham as palavras multidisciplinar, pluridisciplinar, interdisciplinar ou transdisciplinar em seus resumos, evidenciados pelo radical disciplinar. 0 segundo termo poderia conduzir a algum trabalho que remetesse à interdisciplinaridade. Essas duas buscas geraram um total de 529 resumos. Investimos em nova busca junto ao Banco EArte, através da palavra-chave transversal. Foram identificados 103 novos trabalhos e, com a leitura cuidadosa dos respectivos resumos, selecionamos nove trabalhos que julgamos tratarem de práticas interdisciplinares. Todavia, após a leitura dos textos completos dessas nove pesquisas, notamos que não abrangiam a temática de nossa investigação. Assim, nenhum documento resultante da palavra-chave transversal foi acrescido ao nosso corpus documental inicial.

Passamos, então, à leitura atenta dos 529 resumos para procedermos à inclusão ou exclusão dos trabalhos de pesquisa, o que resultou num total de 167 documentos que julgamos, pelos resumos, estarem relacionados a práticas interdisciplinares de EA na educação básica. Buscamos obter os textos completos desses trabalhos e só não conseguimos de um deles. Após uma leitura preliminar dessas 166 dissertações e teses, resultaram apenas 21 trabalhos que, efetivamente, lidaram com práticas interdisciplinares (ou algum grau de interrelação disciplinar) de EA na educação básica.

Esse resultado inicial de nosso levantamento nos surpreendeu. De um total de 2.763 dissertações e teses constantes do Banco EArte, à época do levantamento, apenas 21 foram identificadas como estudos voltados para práticas interdisciplinares na educação básica, ou seja, menos de $1 \%$ do total de documentos. Fizemos uma busca avançada no Banco do EArte, combinando campos temáticos constantes do Banco (Currículos, Programas e Projetos, Processos e Métodos de Ensino Aprendizagem e Recursos Didáticos) com as palavras disciplinar ou integração" ou transversal", mas nada foi acrescido ao nosso levantamento anterior. Assim o corpus documental desta pesquisa ficou constituído por 21 dissertações e teses cujas informações de autoria, título, instituição, ano de defesa e grau acadêmico encontram-se em Apêndice. Constituem dezoito dissertações de mestrado acadêmico, duas teses de doutorado acadêmico e uma dissertação de mestrado profissional

A Figura 1 traz uma síntese da quantidade de trabalhos obtidos, expressos numericamente e por seu percentual em relação ao total de 2.763 trabalhos de 
pesquisa em Educação Ambiental, defendidas no Brasil desde o ano de 1981 até 2012.

Figura 1 - Dados do levantamento de teses e dissertações sobre práticas interdisciplinares junto ao Banco do Projeto EArte

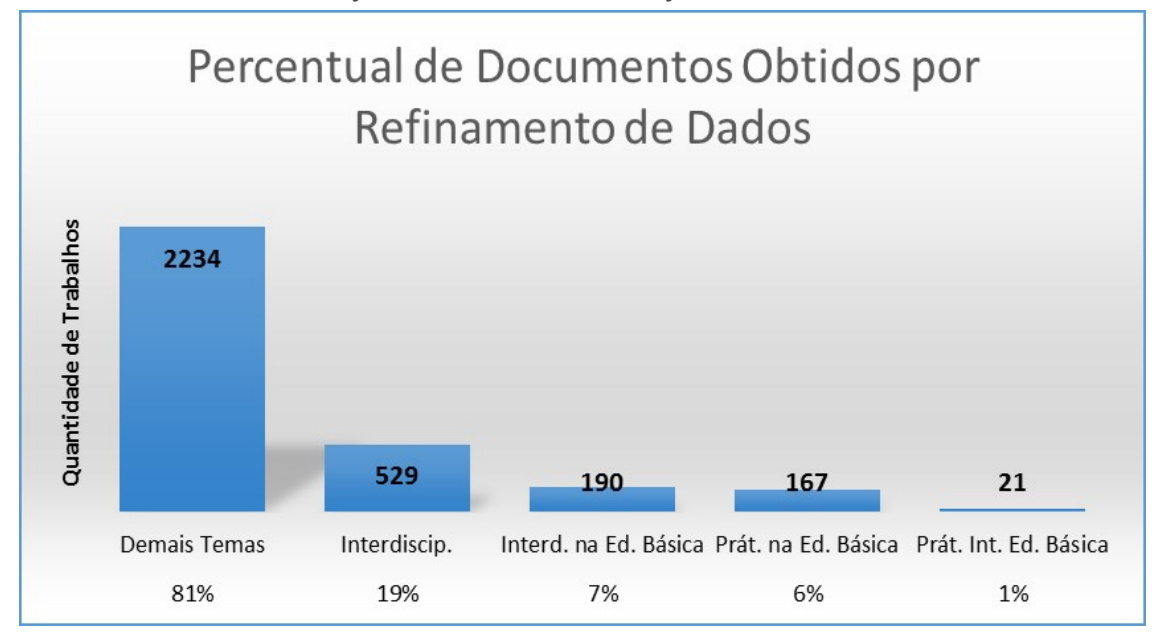

Fonte: Autoria própria com base no Banco de Teses e Dissertações do Projeto EArte (2019).

A distribuição representada na Figura 1 indica a incipiente produção acadêmica destinada às práticas interdisciplinares em EA na educação básica, e evidencia um silêncio de trabalhos investigativos destinado a esse foco temático, o que demanda estudos sobre os motivos que subjazem a essa constatação elucidada por nossa pesquisa. Todavia, Lavaqui e Batista (2007) nos oferecem algumas das possíveis razões para o que foi constatado, ao comentarem que as pesquisas têm mostrado, historicamente, a preocupação interdisciplinar de base epistemológica e empírica ligada mais às pesquisas acadêmicas, do que àquelas voltadas para as práticas educacionais da escola básica.

Para a análise e classificação das práticas interdisciplinares descritas pelos documentos, analisamos três aspectos: 1) base institucional, definida por oito descritores que identificam: o autor, o título do documento, o orientador, a instituição em que se desenvolveu a pesquisa, o programa de pós-graduação, o ano de defesa, o grau acadêmico e a dependência administrativa; 2) prática interdisciplinar, analisada sob nove descritores: ano/série e nível escolar, tipo de escola, disciplinas envolvidas, nível de integração curricular, métodos e estratégias de ensino utilizados, recursos e materiais didáticos, referencial metodológico, o público envolvido e a interação entre ele, e o nível de articulação ou inter-relação entre as disciplinas; 3) manifestação de EA na pesquisa desenvolvida, discutida segundo três descritores: concepção de ambiente, concepção de EA na perspectiva política e concepção de EA na relação curricular.

\section{ANÁLISE DAS PESQUISAS E RESULTADOS}

A primeira defesa de uma dissertação ou tese voltada para a prática interdisciplinar em EA no Brasil ocorreu no ano de 1990, nove anos após a primeira defesa de uma dissertação brasileira em EA (1981). Somente cinco anos após, em 
1995, ocorreu a defesa de outro trabalho. Esse é um dado que nos surpreendeu do ponto de vista da prática interdisciplinar, já que a discussão sobre a interdisciplinaridade circunda os meios acadêmicos brasileiros desde a década de 1970, com as obras de Hilton Ferreira Japiassu e Ivani Catarina Arantes Fazenda, pioneiros no Brasil a respeito de interdisciplinaridade.

Vale destacar que, na segunda metade dos anos 1980, a Secretaria de Estado da Educação de São Paulo formulou novas propostas curriculares para o ensino fundamental (então 1ㅇg grau), tendo a Proposta Curricular de Ciências como eixo integrador a concepção de Ambiente. Estampava-se, ali, uma tendência de, ao menos na disciplina escolar de Ciências, colocar a Educação Ambiental com destaque central no currículo. Quase dez anos depois, em dezembro de 1997, a Educação Ambiental passou a ser considerada nos currículos escolares do ensino fundamental, em virtude da edição dos Parâmetros Curriculares Nacionais e, em particular, do Tema Transversal Meio Ambiente. Além da influência dos PCN, é possível que o impulso observado na produção de pesquisas sobre práticas interdisciplinares em EA tenha, também, decorrido das decisões tomadas na Conferência das Nações Unidas para o Meio Ambiente e Desenvolvimento (Rio92), ocorrida no Rio de Janeiro em 1992 (GONZÁLEZ-GAUDIANO; LORENZETTI, 2009) e da instituição do Programa Agenda 21 por iniciativa do Ministério do Meio Ambiente, a partir do final da década de 1990.

Os anos 2000 apresentaram forte concentração das dissertações e teses aqui estudadas, com um total de dezoito documentos contabilizados. Não houve nenhum trabalho identificado nos anos de 2010 a 2012, o que pode ser observado na Figura 2. A ausência de produção, nos anos de 2010 a 2012, deve ser avaliada em novos estudos e levantamentos, pois pode ter decorrido de atrasos na alimentação do Banco de Teses da Coordenação de Aperfeiçoamento de Pessoal de Nível Superior (Capes), principal base de dados para o Projeto EArte. Até meados da década de 2010, a Capes demorava até dois anos para atualizar os dados do seu Banco de Teses.

Figura 2 - Distribuição das 21 teses e dissertações sobre práticas interdisciplinares de EA pelas décadas em que foram defendidas

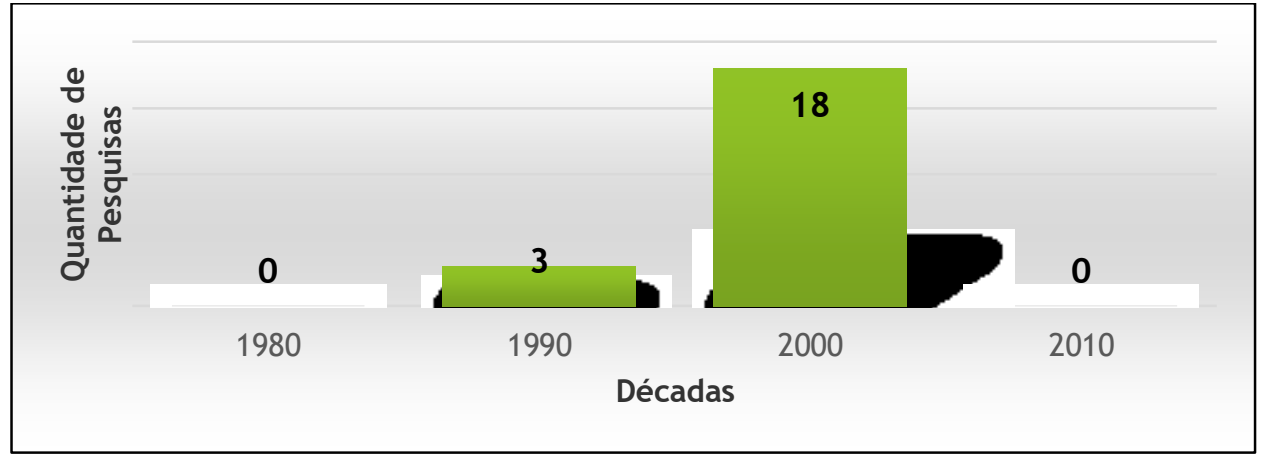

Fonte: Autoria própria (2019).

Os anos de 2004 e 2006 são os únicos que tiveram três defesas, havendo uma queda nos dois anos seguintes, com uma defesa em 2007 e outra em 2008. O último ano identificado nessas produções foi o de 2009 , contribuindo com duas pesquisas para o tema investigado, o que igualmente ocorreu com os anos de 2002, 2003 e 2005. Muito embora seja visível um discreto aumento na produção 
acadêmica brasileira a partir do ano de 2002, ainda assim, o cenário pouco avança nesse contexto de pesquisa, o que significa uma média de duas pesquisas/ano, o que descortina um campo de trabalho que ainda está por merecer um volume maior de pesquisas.

Quanto às Instituições de Ensino Superior, a Universidade Federal da Paraíba (UFPB) e a Universidade Luterana do Brasil (Ulbra) foram responsáveis por três trabalhos cada uma, enquanto a Universidade Estadual Paulista Júlio de Mesquita Filho (Unesp), campus de Bauru, foi responsável por dois trabalhos. Os demais trabalhos foram defendidos em treze instituições distintas, com apenas uma defesa tendo ocorrido em cada uma.

Os programas de pós-graduação em Educação contribuíram com $24 \%$ dos trabalhos, com um total de cinco pesquisas. Seguem-se dois trabalhos em cada um dos quatro seguintes programas de pós-graduação: Geografia, Educação para a Ciência, Ensino de Ciências e Matemática e Ciência Ambiental. Os demais documentos se dividem em seis programas de pós-graduação, cada um contando com uma única defesa: Ensino e História de Ciências da Terra, Oceanografia, Ecologia e Manejo de Recursos Naturais, Desenvolvimento e Meio Ambiente, Planejamento e Gestão Ambiental e Psicologia. A diversidade de programas de pós-graduação em que foram produzidas as pesquisas sinalizam para uma rica possibilidade de produção de trabalhos interdisciplinares fomentados pelas características de cada um desses programas, diferentes entre si e interessados nas práticas escolares em EA.

A unidade federativa que concentrou um número maior de pesquisas foi o estado de São Paulo, com cinco trabalhos, seguido pelo estado do Rio Grande do Sul, com quatro, o estado da Paraíba, com três, e o estado do Rio de Janeiro, com duas pesquisas. Os demais estados, Acre, Mato Grosso, Distrito Federal, Minas Gerais, Espírito Santo, Paraná e Ceará foram representados com um trabalho cada.

Quanto às características específicas da prática interdisciplinar em EA, não houve predominância de pesquisas realizadas em algum tipo de escola pública ou privada: nove pesquisas foram desenvolvidas em escolas públicas e onze em escolas privadas. Houve forte concentração de trabalhos desenvolvidos nos anos iniciais do ensino fundamental (dez trabalhos), seguido dos anos finais do ensino fundamental (oito trabalhos), ensino médio (seis trabalhos) e educação infantil (um trabalho). Várias pesquisas envolveram turmas de alunos de três ou quatro anos escolares do mesmo nível escolar, dando indícios de que todos os alunos daquele segmento escolar participaram das práticas. Alguns trabalhos envolveram turmas de alunos dos dois segmentos do ensino fundamental, ou turmas dos anos finais do ensino fundamental e turmas do ensino médio.

Quanto às disciplinas envolvidas nas práticas interdisciplinares, Geografia esteve presente em dezessete trabalhos; Português, em dezesseis; Matemática em catorze; Artes em treze; Ciências em doze; História em onze trabalhos. Outras disciplinas participaram em menor frequência no conjunto de trabalhos, como Biologia, Educação Física, Filosofia, Física, Inglês, Música, Religião e Sociologia, geralmente em um ou dois trabalhos, apenas.

Na maioria das dissertações e teses, as práticas envolveram a participação de um número significativo de disciplinas do currículo escolar. Dentre os 21 documentos, onze envolveram desde seis disciplinas, o que ocorreu em cinco 
trabalhos, até doze disciplinas (um trabalho). Oito trabalhos abrangeram três, quatro ou cinco disciplinas. Não identificamos nenhum trabalho que tenha envolvido apenas uma ou duas disciplinas nas práticas e em dois trabalhos não foi possível fazer tal inferência.

Os métodos e estratégias de ensino utilizados nas práticas se dividiram entre tema gerador (nove trabalhos), método de projeto (sete trabalhos) e estudo do meio (quatro trabalhos). Muito embora o eixo desencadeador da prática educativa interdisciplinar em EA possa se apresentar dividido entre estudo temático, projeto ou estudo do meio, não encontramos diferenciação no que se refere ao modo como esses recursos foram utilizados nas respectivas práticas. De modo geral, todos os trabalhos partiram de alguma temática do contexto da EA, propuseram estudos ou projetos (incluídos os estudos do meio) a serem realizados pelos alunos e, em alguns casos, até mesmo planejados pelos alunos com orientação dos professores.

Quanto aos recursos e materiais didáticos utilizados, foram os comumente utilizados em sala de aula como cartolina, tinta, elaboração de painéis, apresentação teatral, elaboração de textos etc. Houve, também, passeios externos e visitações a equipamentos públicos, alguns no entorno da escola ou, ainda, no mesmo município em que a escola estava localizada; poucos deles realizados em outra cidade. Alguns trabalhos lançaram mão de recursos didáticos não comumente utilizados no ambiente escolar como, por exemplo, imagens de satélite, fotografias aéreas, kit para análise da água entre outros.

Do ponto de vista do referencial teórico-pedagógico que deu suporte aos processos de ensino e aprendizagem, encontramos referenciais de caráter construtivista/cognitivista (onze trabalhos) ou na perspectiva sociocultural/histórico-crítica (seis trabalhos). Em quatro trabalhos não foi possível identificar um referencial pedagógico explícito ou predominante.

Quanto ao tipo de participação dos alunos nas práticas interdisciplinares, apresentou-se uma relação hierárquica no que se refere à decisão do tema a ser estudado, muito embora da parte dos estudantes a relação estabelecida para com a proposta foi de parceria, denotando motivação e interesse para a aprendizagem. Essa constatação nos conduz à reflexão sobre a prática interdisciplinar, já que a interdisciplinaridade supõe uma relação horizontal entre os envolvidos, o que não ocorreu em $2 / 3$ das práticas analisadas. Acreditamos que esse seja um ponto a ser considerado quando se pretende trabalhar nas unidades escolares com a interdisciplinaridade no contexto da EA, seja na previsão dos projetos pedagógicos, no planejamento dos professores ou ainda nas intenções dos pesquisadores.

Quanto à participação dos familiares, comunidade e profissionais de outras áreas, não ultrapassou o nível cooperativo, destinando-se a esses atores ações pontuais no processo educativo, seja através do fornecimento de materiais, acompanhamento das pesquisas escolares dos alunos, ministrar palestras, além de outras formas de participação.

Em relação à inter-relação entre as disciplinas envolvidas nas práticas, em três trabalhos as práticas foram por nós consideradas de nível pluridisciplinar e, em 17 trabalhos, consideramos práticas de fato interdisciplinares, não obstante duas tenham se autodeclarado como de natureza transdisciplinar, no que discordamos 
dos respectivos autores. Em um trabalho não conseguimos dados suficientes para tal classificação.

Com respeito aos aspectos da Educação Ambiental, depreendemos da análise das pesquisas e práticas ali tratadas que a concepção de ambiente integrado se destacou entre as demais, estando presente em treze trabalhos, ficando sete deles na categoria ambiente integrado com perspectiva utilitarista. Quanto à perspectiva política de Educação Ambiental, consideramos onze trabalhos em sintonia com a macrotendência crítica, seguida por sete pesquisas na macrotendência pragmática e uma pesquisa que julgamos evidenciar ora aspectos da perspectiva crítica, ora aspectos da perspectiva pragmática. Somente um trabalho foi por nós considerado alinhado à macrotendência conservacionista. Quanto à manifestação curricular da Educação Ambiental, foram identificados dez trabalhos como elemento essencial, oito como elemento transversal e dois como elemento complementar. No conjunto desses descritores sobre ambiente e EA, encontramos um trabalho cujos dados não foram suficientes para empreender as classificações.

\section{CONSIDERAÇÕES FINAIS}

O trabalho investigativo que realizamos possibilitou traçar um panorama sobre as práticas interdisciplinares em Educação Ambiental na educação básica, a partir das descrições dos autores presente nas teses e dissertações que trataram desse tema.

No processo de seleção das 21 dissertações e teses que compuseram o corpus documental desta pesquisa, encontramos um número bem maior de trabalhos que abrangeram práticas interdisciplinares, mas no sentido de evidenciar as representações, as percepções ou concepções dos profissionais do ensino acerca dessa temática, sem contudo estudar os processos de ensino e aprendizagem envolvidos na prática interdisciplinar propriamente dita.

O resultado da pequena quantidade de dissertações e teses que dedicaram seus estudos às práticas interdisciplinares indica a necessidade de que mais pesquisadores se dediquem ao estudo das implementações da interdisciplinaridade na educação básica. No início da nossa investigação acreditávamos encontrar um número bem maior de pesquisas que dedicassem seus estudos a esse tema. $O$ resultado nos causou surpresa, por considerarmos a EA um universo de tratamento interdisciplinar, o que é reforçado pelas orientações curriculares oficiais e, também, pelas políticas nacionais de Educação Ambiental.

Segundo nossa percepção, ainda estamos num estágio precedente a investigações que se voltem mais intensamente para as práticas interdisciplinares em EA na educação básica, o que podemos atribuir a alguns fatores descritos pelos pesquisadores em seus documentos como, por exemplo, a constatação da necessidade da formação continuada para subsidiar o trabalho educativo a ser realizado pelos professores no que se refere a questões relativas ao ambiente, bem como ao exercício da Educação Ambiental, da transversalidade e da interdisciplinaridade em contexto escolar.

Um fator limitador para a implementação de processos escolares de Educação Ambiental numa perspectiva interdisciplinar e crítica diz respeito à formação inicial 
e continuada de professores. Barros, Queiroz e Souza (2019), após realizarem uma pesquisa do tipo Estado da Arte sobre a formação de professores em Educação Ambiental, segundo trabalhos publicados em periódicos brasileiros da área de ensino entre 2005 e 2017, concluem:

[...] que há a necessidade de aumentar as discussões acerca da formação de professores para a educação ambiental, nos seguintes aspectos: a reflexão crítica, a autonomia, valorização da diversidade, interdisciplinaridade, discussões políticas, os aspectos das relações ciência, tecnologia sociedade e ambiente (CTSA) (BARROS; QUEIROZ; SOUZA, 2019, p. 199).

Outro fator dificultador identificado em nossas análises deriva da organização escolar prevalecente, a qual tem um forte lastro de cultura curricular disciplinar e exigências decorrentes, como o cumprimento linear das matérias curriculares, a hierarquização de algumas disciplinas, o curto período de tempo destinado à elaboração do projeto pedagógico escolar, do planejamento anual e mensal docente, a intensa burocratização, a divisão dos tempos e espaços escolares e a quase inexistente possibilidade de articulação dos docentes.

Esse fato anuncia a necessidade de uma ação conjunta sob os aspectos da formação inicial dos professores e apoio das políticas públicas educacionais, para que venham proporcionar condições de que os trabalhos interdisciplinares sejam possíveis de se efetivarem e os professores tenham condições de exercer essa prática caso queiram, haja vista os ganhos que os relatos das pesquisas evidenciaram.

Contudo, observamos que o fato de nos depararmos com uma escola de organização curricular tradicional não inviabilizou a prática interdisciplinar nos trabalhos analisados. É possível que, nas escolas em que as pesquisas aconteceram, a prática interdisciplinar não perdure por muito tempo, tendo se efetivado tão somente durante a realização das respectivas pesquisas. $\mathrm{O}$ fato de não se encontrar uma organização escolar que se adeque a esse tipo de ação pedagógica é, talvez, o fator mais limitante, muito embora saibamos que, desde final da década de 1990, as orientações curriculares para a educação básica incentivam práticas transdisciplinares ou interdisciplinares.

A viabilidade da realização de práticas interdisciplinares numa escola com estrutura tradicional não se limita ao campo da Educação Ambiental apenas. A título de exemplo, mencionamos o trabalho de Lima e colaboradores (2019), que aplicaram uma proposta pedagógica abrangendo as disciplinas de Geografia, História, Sociologia, Matemática, Química e Física. As atividades consistiram de práticas investigativas, experimentais e debates a respeito do aproveitamento da energia potencial em uma usina hidrelétrica e discussões sobre transformações reversíveis e irreversíveis, além do custo humano, ambiental e monetário da geração e utilização da eletricidade. Os autores destacaram que, devido à falta de experiências com ações interdisciplinares dos professores envolvidos, as atividades inicialmente planejadas precisaram de ajustes, bem como houve restrição temporal para realização das mesmas. Todavia, concluíram que ocorreu esclarecimento do conceito de energia por parte dos estudantes e que "[...] a interdisciplinaridade é uma ferramenta importante e que obtém bons resultados numa concepção de ensino diferente do tradicional" (LIMA et al., 2019, p.1). 
Tomando por base as análises desta pesquisa de Estado da Arte e experiências similares como as de Lima e colaboradores (2019), podemos considerar que o exercício da prática interdisciplinar traz algumas exigências, como qualquer outra prática de ensino. Entretanto, por se tratar de uma prática inovadora, do ponto de vista da articulação das disciplinas e dos profissionais envolvidos, é necessário ter em conta algumas peculiaridades que ela apresenta, para que possa ter maior fluência nas nossas escolas. Em geral, os autores das dissertações e teses analisadas relatam ser essencial que ocorram momentos de reuniões iniciais do corpo pedagógico da escola para a troca de ideias entre os envolvidos, como também observam a necessidade de se realizar um trabalho voltado para a formação dos profissionais implicados no projeto interdisciplinar, para que compreendam o exercício da interdisciplinaridade e se apropriem de várias noções a respeito da temática ambiental. Esse trabalho inicial deve ser pautado por estudos e questões trazidas pelos professores e pesquisadores, de modo a conduzir uma atitude reflexiva do grupo sobre o que significa a aplicabilidade da interdisciplinaridade e da EA no ambiente escolar, conscientizando para a necessidade de um processo crítico de reflexão-ação-reflexão contínuo.

Outra preocupação reside na parceria e necessária horizontalidade presente nas relações interpessoais e interprofissionais, indispensáveis nesse processo, movidas por uma atitude interdisciplinar, que exige espírito de abertura ao outro, acolhimento e trabalho coletivo colaborativo, além do necessário domínio de conteúdo de cada área específica. A isto deve-se acrescer a disponibilidade pessoal e profissional para o exercício de construção conjunta de uma proposta educativa composta por várias disciplinas, a adequação de seus propósitos ao desenvolvimento sociocognitivo dos alunos, o resgate das experiências pessoais dos estudantes, dos conceitos ou das noções conceituais que já possuem, de modo a traçar um cenário propício para a composição dos conteúdos de ensino a serem estudados.

Igualmente, ressaltamos que a dinamicidade e singularidade da experiência do trabalho pedagógico interdisciplinar o torna único e irreprodutível na sua manifestação. É possível replicar os mesmos projetos de ensino ou estudos temáticos, todavia esses não se comportarão de modo idêntico na sua condução, dada as características da formação de cada grupo, seu amadurecimento na condução do trabalho, as características e experiências individuais de cada uma das pessoas envolvidas e do tempo sócio-histórico em que as práticas acontecem.

Como sucessos encontrados, os relatos dos pesquisadores destacam o interesse e envolvimento dos professores e dos alunos com as questões estudadas. Também se referem às mudanças de concepções sobre ambiente e EA observadas nos profissionais envolvidos; os pesquisadores descreveram ter constatado que a EA escolar acontecia em momentos pontuais, ocasionais ou sequer era contemplada de maneira explícita e que as concepções de ambiente encontradas nas práticas escolares tendiam para concepções conservadoras ou pragmáticas. Assim, relatam que boa parte das pesquisas possibilitaram mudanças nas práticas e/ou concepções de EA que vinham se processando nas escolas. Outro aspecto positivo residiu no trabalho com a comunidade, as situações foram colaborativas, as pessoas se envolviam com os alunos e a escola, de modo a auxiliar em tudo que era necessário. A escola e o ambiente escolar se apresentaram enquanto locais de aprendizagem gratificantes e não impositivos, o que tornou as ações pedagógicas 
educativas agradáveis, ocorrendo uma boa compreensão dos conteúdos disciplinares por parte dos estudantes, fortalecendo os laços de confiança e companheirismo entre esses e os docentes. As relações interdisciplinares existentes entre as disciplinas e os conteúdos envolvidos fluíram de modo natural, favorecendo a compreensão dos alunos quanto a uma visão complexa do ambiente e suas problemáticas.

No conjunto de 21 documentos analisados, identificamos lacunas em relação aos níveis do ensino médio e educação infantil. Tomando-se as dissertações e teses em EA, produzidas no Brasil entre 1981 e 2012, abrangendo um universo de mais de duas mil pesquisas defendidas em mais de três décadas, localizamos apenas quatro pesquisas tratando de práticas interdisciplinares no ensino médio, e apenas uma para a educação infantil. Embora esses dois níveis de ensino chamem a atenção, indicamos que sejam intensificados estudos voltados para a efetivação das práticas interdisciplinares em Educação Ambiental na educação básica em geral, pois as práticas interdisciplinares abrangendo o ensino fundamental também estiveram pouco representadas no conjunto total de pesquisas em EA.

Consideramos preocupante esse cenário, já que se passou mais de meio século das discussões acerca da necessidade da interdisciplinaridade abordada por diversos países do mundo, sobretudo por ocasião da reunião da Organização para a Cooperação e Desenvolvimento Econômico (OCDE), realizada no ano de 1970, em Nice, na França (OCDE, 1973), além das políticas curriculares oficiais em âmbito nacional publicadas desde a segunda metade da década de 1990, com os Parâmetros Curriculares Nacionais e, também, das políticas e diretrizes nacionais sobre Educação Ambiental.

Nosso estudo sugere novas pesquisas que envolvam essa temática - práticas interdisciplinares em Educação Ambiental na educação básica -, que busquem não só intensificar estudos sobre a implementação das práticas interdisciplinares na educação escolar básica, mas que procurem evidenciar e estudar os fatores que contribuíram para a realização e sucesso dos processos de ensino e aprendizagem empreendidos. 


\title{
Interdisciplinary practices in environmental education in basic education: what brazilian academic researches indicate from 1981 to 2012
}

\begin{abstract}
The present research aims at analyzing interdisciplinary practices in Environmental Education implemented in basic education (primary, middle and high school) described and/or suggested in Brazilian theses and dissertations. The multidimensionality present in environmental issues and the importance of the approach of Environmental Education in all levels of education, from an interdisciplinary perspective, are the motivating factors for choosing the subject of this study. It was our intent to investigate the conceptions of Interdisciplinary, Environment and Environmental Education revealed in identified academic researches. Out of 2.763 presented theses between 1981 and 2012 accounted in Banco de Teses EArte, just 21 related to this subject matter. These documents were read, depicted and classified according to institutional data (author, adviser, submission year, institution, graduate program, state, administrative organization, academic degree) and under aspects of interdisciplinary practice of Environmental Education (school year, school type, subject areas, teaching methods and strategies, resources and teaching material, curricular integration, pedagogical references, public concerned, and their relation to the level of discipline integration, environment conception, Environmental Education conception and curricular display. The researches highly concentrated in the 2000s. Most practices analyzed focused on the first years of basic school, and evolved from inducing subjects or study projects. Teaching materials adopted were the commonly used in schools, as well as outdoor activities related to the subject matter. Pedagogical actions obeyed the schools curricular proposals and the most involved subjects (always integrated with others) were Geography and Portuguese, followed by Mathematics, Science, History and Arts. Parents and community take a cooperative role in the practice and there is a hierarchical relation between teachers, researchers and students when deciding on the proposed assignment. Yet, there is an intense participation of students in accepting the proposal and developing the activities. Eighteen practices were classified as interdisciplinary and three evolved in a multidisciplinary level. In the practices, the conception of integrated environment and Environmental Education from a critical perspective prevailed and it was displayed as an essential element to the school curriculum. As researches revealed, although teachers showed interest in Environmental Education and in interdisciplinary practice, they were not prepared to work with them, which suggests a need for investing in continuous training and revision of basic teaching training courses.
\end{abstract}

KEYWORDS: Environmental Education. Interdisciplinary Practices. Pedagogical Practices. Basic Education. State of the Art. 


\section{REFERÊNCIAS}

AMARAL. I. A. do. Programas e ações de formação docente em Educação Ambiental. In: TAGLIEBER, J. E.; GUERRA, A. F. S. (Orgs.). Pesquisas em Educação Ambiental: pensamentos e reflexões de pesquisadores em Educação Ambiental. Pelotas: Ed. Universitária/UFPEL, 2004. p. 145-167.

AMARAL. I. A. do. Modalidades curriculares de Educação Ambiental. Curitiba: SEE/Coordenação de Estudos e Pesquisas Educacionais/Agenda 21 Escolar, 2005.

BARROS, T. G. E.; QUEIROS, W. P.; SOUSA, D. C. Modelos formativos nas pesquisas sobre formação de professores em educação ambiental: enfoques e limitações. ACTIO, Curitiba, v. 4, n. 1, p. 184-205, 2019. Disponível em: https://periodicos.utfpr.edu.br/actio/article/view/8048/6104. Acesso em 05 jun. 2019.

BRASIL. Ministério da Educação e do Desporto. Parâmetros curriculares Nacionais. Brasília: MEC/SEF, 1996. 10v.

BRASIL. Ministério do Meio Ambiente. Recomendações de Tbilisi. Disponível em: https://www.mma.gov.br/informma/item/8065-recomenda\%C3\%A7\%C3\%B5esde-tbilisi.html. Acesso em: 09 jul. 2020.

BRÜGGER, P. Educação ou adestramento ambiental. 3 ed. rev. e ampliada. Chapecó: Argos; Florianópolis: Letras Contemporâneas, 2004. 200 p.

GONZÁLEZ-GAUDIANO, E.; LORENZETTI, L. Investigação em Educação Ambiental na América Latina: mapeando tendências. Educação em Revista, Belo Horizonte, v. 25, n. 3, p.191-211, 2009. Disponível em:

https://www.scielo.br/pdf/edur/v25n3/10.pdf. Acesso em: 09 jul. 2020.

FAZENDA, I. C. A. Interdisciplinaridade: um projeto em parceria. São Paulo. Loyola, 1995. $174 \mathrm{p}$.

JANSTCH, E. Vers l'interdisplinarité et la transdisciplinarité dans l'enseignement et I'innovation. In: OCDE (Organisation de Coopération et de Développement Economique). L'Interdisciplinarité: problèmes d'enseignement et de recherche dans les universités. Paris: Unesco/OCDE, 1973. p. 98-125.

JAPIASSU, H. Interdisciplinaridade e patologia do saber. Rio de Janeiro: Imago, 1976. $220 \mathrm{p}$.

JAPIASSU, H. A questão da interdisciplinaridade. In: SEMINÁRIO INTERNACIONAL SOBRE REESTRUTURAÇÃO CURRICULAR, 1., 1994, Porto Alegre. Anais [...] Porto Alegre: Secretaria Municipal de Educação, 1994.

LAVAQUI, V.; BATISTA, I. L. Interdisciplinaridade em Ensino de Ciências e de Matemática no Ensino Médio. Ciência \& Educação, Bauru, v. 13, n. 3. p. 399-420, 2007. Disponível em: https://www.scielo.br/pdf/ciedu/v13n3/a09v13n3.pdf. 
LAYRARGUES, P. P. Educação Ambiental com compromisso social. O desafio da superação das desigualdades. In: LOUREIRO, C. F. B. et al. (Orgs.). Repensar a Educação Ambiental. São Paulo: Cortez. 2009. p. 11-32.

LAYRARGUES, P. P.; LIMA, G. F. C. As macrotendências político-pedagógicas da educação ambiental brasileira. Ambiente \& Sociedade, São Paulo, v. 17, n. 1, p. 23-40, jan./mar. 2014. Disponível em:

https://www.scielo.br/pdf/asoc/v17n1/v17n1a03.pdf. Acesso em: 09 jul. 2020.

LIMA, E. B. et al. Uma proposta interdisciplinar a partir do conceito de energía potencial e suas transformações. ACTIO, Curitiba, Edição Especial, v. 4, n. 1, p. 11, 2019. Disponível em:

https://periodicos.utfpr.edu.br/actio/article/view/10715/6650. Acesso em: 05 jun. 2020.

LIMA, G. F. C. Questão ambiental e Educação: contribuições para o debate. Ambiente \& Sociedade, São Paulo, Ano II, s/v, n. 5, p. 135-153, 2o sem. 1999. Disponível em: https://www.scielo.br/scielo.php?script=sci_arttext\&pid=S1414753X1999000200010\&Ing=es\&nrm=iso\&tlng=pt. Acesso em: 09 jul. 2020.

MEGID NETO, J. Educação Ambiental como campo de conhecimento: a contribuição das pesquisas acadêmicas para sua consolidação no Brasil. Pesquisa em Educação Ambiental, Rio Claro, v. 4, n. 2, p. 95-110, jan. 2009. Disponível em: file://C:/Users/Jorge/Downloads/6193-Texto\%20do\%20artigo-31563-2-1020160317.pdf. Acesso em: 09 jul. 2020.

NOGUEIRA, M. L. S. L. S. Práticas interdisciplinares em Educação Ambiental na educação básica: o que nos revelam as pesquisas acadêmicas brasileiras (19812012). 2016. 349 f. Tese (Doutorado em Educação) - Faculdade de Educação, Universidade Estadual de Campinas, Campinas, 2016.

ORGANISATION DE COOPÉRATION ET DE DÉVELOPPEMENT ECONOMIQUE OCDE. L'Interdisciplinarité: problèmes d'enseignement et de recherche dans les universités. Centre pour la Recherché et l'Innovation dans l'Enseignement. Nice, France: OCDE, 1973. $334 \mathrm{p}$.

PIAGET, J. Epistemologie des Rélations Interdisciplinaires. In: OCDE (Organisation de Coopération et de Développement Economique). L'Interdisciplinarité: problèmes d'enseignement et de recherche dans les universités. Paris: Unesco/OCDE, 1973. p. 131-144.

RINK, J. Ambientalização curricular na Educação Superior: tendências da pesquisa brasileira (1987-2009). 2014. 254 f. Tese (Doutorado em Educação) Faculdade de Educação, Universidade Estadual de Campinas, Campinas, 2014. 
APÊNDICE - Informações das 21 teses e dissertações do corpus documental

\begin{tabular}{|c|c|c|c|c|}
\hline Autor & Título & Ano & IES & $\begin{array}{c}\text { Gra } \\
u\end{array}$ \\
\hline $\begin{array}{l}\text { Renata Gomes } \\
\text { de Abreu }\end{array}$ & \begin{tabular}{|} 
Uso de ecossistemas florestais como instrumento \\
de ensino e pesquisa na Educação rural: o caso \\
do projeto Floresta das Crianças
\end{tabular} & 2009 & UFAC & M \\
\hline $\begin{array}{l}\text { Vera Alice Pexe } \\
\text { Alves }\end{array}$ & $\begin{array}{c}\text { O ensino interdisciplinar na } 5 \text { a série do } 1 \text { o grau do } \\
\text { Colégio Master: a comunidade tradicional de } \\
\text { Bom Sucesso em uma perspectiva ambiental }\end{array}$ & 1997 & UFMT & $M$ \\
\hline $\begin{array}{l}\text { José Rodrigues } \\
\text { Alves Filho }\end{array}$ & $\begin{array}{c}\text { Educação Ambiental no Ensino Fundamental: } \\
\text { reflexões sobre as práticas escolares em três } \\
\text { escolas de Teresina }\end{array}$ & 2009 & ULBRA & M \\
\hline $\begin{array}{l}\text { Adriana Rosinha } \\
\text { Araldi }\end{array}$ & $\begin{array}{c}\text { A construção do conhecimento, da ética e da } \\
\text { cidadania: a crise socioambiental imprimindo } \\
\text { uma nova face à práxis educativa }\end{array}$ & 2000 & UFRGS & M \\
\hline $\begin{array}{l}\text { Washington Luiz } \\
\text { Assunção }\end{array}$ & $\begin{array}{l}\text { A Educação Ambiental como um processo } \\
\text { interdisciplinar: uma experiência com a coleta } \\
\text { seletiva de lixo na Escola Estadual Joaquim } \\
\text { Saraiva-Uberlândia-MG }\end{array}$ & 1995 & UFU & M \\
\hline $\begin{array}{l}\text { Fabiana } \\
\text { Modesto } \\
\text { Dacache }\end{array}$ & $\begin{array}{l}\text { Uma proposta de Educação Ambiental utilizando } \\
\text { o lixo como tema interdisciplinar }\end{array}$ & 2004 & UFF & M \\
\hline $\begin{array}{l}\text { Célia Regina } \\
\text { Auler Pereira } \\
\text { Furuta }\end{array}$ & $\begin{array}{l}\text { Arborização urbana como tema para um } \\
\text { programa de Educação Ambiental }\end{array}$ & 2001 & UNESP & M \\
\hline $\begin{array}{l}\text { Vera Kern } \\
\text { Hoffmann }\end{array}$ & $\begin{array}{l}\text { Uma proposta interdisciplinar de Educação, nas } \\
\text { primeiras quatro séries do Ensino Fundamental, } \\
\text { na perspectiva do desenvolvimento sustentável }\end{array}$ & 2003 & ULBRA & M \\
\hline $\begin{array}{l}\text { Maria de } \\
\text { Lourdes Lima }\end{array}$ & $\begin{array}{c}\text { Sensibilização ambiental no processo educativo: } \\
\text { o tema dos resíduos sólidos urbanos no programa } \\
\text { curricular de 1a série do Ensino Fundamental }\end{array}$ & 2003 & UEM & $\mathrm{M}$ \\
\hline $\begin{array}{l}\text { Maria das } \\
\text { Graças Ferreira } \\
\text { Lobino }\end{array}$ & $\begin{array}{c}\text { Influência dos diferentes saberes e concepções } \\
\text { na práxis ambiental docente: limites e } \\
\text { possibilidades }\end{array}$ & 2002 & UFES & M \\
\hline $\begin{array}{l}\text { Luis Gustavo } \\
\text { Lucatto }\end{array}$ & $\begin{array}{c}\text { Construção coletiva interdisciplinar em Educação } \\
\text { Ambiental: a microbacia hidrográfica do Ribeirão } \\
\text { dos Peixes como tema gerador }\end{array}$ & 2005 & UNESP & M \\
\hline $\begin{array}{c}\text { Josefina Reis de } \\
\text { Moraes }\end{array}$ & $\begin{array}{l}\text { A construção de uma proposta pedagógica } \\
\text { transdisciplinar como eixo de mudança em um } \\
\text { processo participativo de Gestão Ambiental }\end{array}$ & 2006 & UCB & M \\
\hline $\begin{array}{c}\text { Cristine } \\
\text { Gerhardt } \\
\text { Rheinheimer }\end{array}$ & $\begin{array}{c}\text { Tecendo a Educação Ambiental através do estudo } \\
\text { do meio ambiente na escola }\end{array}$ & 2004 & Ulbra & M \\
\hline $\begin{array}{l}\text { Miguel Angelo } \\
\text { Thompson Rios }\end{array}$ & $\begin{array}{l}\text { O litoral como tema de investigação no Ensino } \\
\text { Médio e o desenvolvimento de conteúdos } \\
\text { conceituais, procedimentais e atitudinais: uma } \\
\text { proposta curricular }\end{array}$ & 2004 & USP & $\mathrm{D}$ \\
\hline $\begin{array}{l}\text { Ilka Maria Zoza } \\
\text { Rocha }\end{array}$ & Escola Vila: pedagogia da sustentabilidade & 2007 & UNIFOR & M \\
\hline $\begin{array}{l}\text { Renato } \\
\text { Rodrigues }\end{array}$ & $\begin{array}{c}\text { Ecoalfabetização: uma experiência de } \\
\text { aprendizagem em Educação Ambiental com } \\
\text { escola pública e comunidade do município de } \\
\text { Ubatuba - SP }\end{array}$ & 2006 & UNITAU & MP \\
\hline
\end{tabular}




\begin{tabular}{|c|c|c|c|c|}
\hline Autor & Título & Ano & IES & $\begin{array}{c}\text { Gra } \\
\text { u }\end{array}$ \\
\hline $\begin{array}{c}\text { Sandra Regina } \\
\text { Pinto dos Santos }\end{array}$ & $\begin{array}{c}\text { Projeto Ave: um espaço interdisciplinar de } \\
\text { Educação Ambiental do curso normal }\end{array}$ & 1990 & PUCRJ & M \\
\hline $\begin{array}{c}\text { Vânia Maria } \\
\text { Nunes dos } \\
\text { Santos }\end{array}$ & $\begin{array}{c}\text { Formação de professores para o estudo do } \\
\text { ambiente: projetos escolares e a realidade } \\
\text { socioambiental local. }\end{array}$ & 2006 & $\begin{array}{c}\text { UNICAM } \\
\text { P }\end{array}$ & D \\
\hline $\begin{array}{c}\text { Shirley E. do } \\
\text { Nascimento } \\
\text { Silva }\end{array}$ & $\begin{array}{c}\text { As escolas vão aos manguezais: uma experiência } \\
\text { participativa em Educação Ambiental no } \\
\text { município de Bayeux - PB }\end{array}$ & 2008 & UFPB & $\mathrm{M}$ \\
\hline $\begin{array}{c}\text { Dinabel Alves } \\
\text { Cirne Vilas Boas }\end{array}$ & $\begin{array}{c}\text { Uma experiência em Educação Ambiental: } \\
\text { redesenhando o espaço e as relações escolares }\end{array}$ & 2002 & UFPB & $\mathrm{M}$ \\
\hline $\begin{array}{c}\text { André Souto } \\
\text { Witter }\end{array}$ & $\begin{array}{c}\text { Educação Ambiental como projeto: } \\
\text { interpretação, reflexão, ação e o } \\
\text { desenvolvimento do turismo local }\end{array}$ & 2005 & UFPB & $\mathrm{M}$ \\
\hline
\end{tabular}

Fonte: Autoria própria. Informações completas constam em Nogueira (2016).

Recebido: 25 maio 2020

Aprovado: 10 jul. 2020

DOI: $10.3895 /$ actio.v5n2.12449

Como citar:

NOGUEIRA, M. L. de S. L. S.; MEGID NETO, J. Práticas interdisciplinares em Educação Ambiental na educação básica: o que indicam as pesquisas acadêmicas brasileiras (1981-2012). ACTIO, Curitiba, v. 5, n.

2, p. 1-21, maio/ago. 2020. Disponível em: <https://periodicos.utfpr.edu.br/actio>. Acesso em: XXX Correspondência:

Marilac Luzia de Souza Leite Sousa Nogueira

Avenida Bertrand Russell, n. 801, Cidade Universitária Zeferino Vaz, Campinas, São Paulo, Brasil.

Direito autoral: Este artigo está licenciado sob os termos da Licença Creative Commons-Atribuição 4.0 Internacional. 